\title{
Exploring Marine Resources for Bioactive Compounds
}

Authors

Affiliations
Paula Kiuru ${ }^{1}$, M. Valeria D’Auria² ${ }^{2}$ Christian D. Muller ${ }^{3}$, Päivi Tammela ${ }^{4}$, Heikki Vuorela ${ }^{5}$, Jari Yli-Kauhaluoma ${ }^{1}$

${ }^{1}$ Division of Pharmaceutical Chemistry and Technology, Faculty of Pharmacy, University of Helsinki, Finland

${ }^{2}$ Department of Pharmacy, University of Naples Federico II, Naples, Italy

${ }^{3}$ Laboratoire d'Innovation Thérapeutique UMR CNRS 7200, Faculté de Pharmacie, Université de Strasbourg, Illkirch, France

${ }^{4}$ Centre for Drug Research, Faculty of Pharmacy, University of Helsinki, Finland

${ }^{5}$ Division of Pharmaceutical Biosciences, Faculty of Pharmacy, University of Helsinki, Finland

\section{Key words}

- marine drug discovery

- biodiversity

- microalgae

- cyanobacteria

- macroalgae

- fungi

- marine invertebrates

- marine bioactive compounds

\section{Abstract \\ $\nabla$}

Biodiversity in the seas is only partly explored, although marine organisms are excellent sources for many industrial products. Through close cooperation between industrial and academic partners, it is possible to successfully collect, isolate and classify marine organisms, such as bacteria, fungi, micro- and macroalgae, cyanobacteria, and marine invertebrates from the oceans and seas globally. Extracts and purified compounds of these organisms can be studied for several therapeutically and industrially significant biological activities, including anticancer, anti-inflammatory, antiviral, antibacterial, and anticoagulant activities by applying a wide variety of screening tools, as well as for ion channel/receptor modulation and plant growth regulation. Chromatographic isolation of bioactive compounds will be followed by structural determination. Sustainable cultivation methods for promising organisms and

\section{Introduction}

$\nabla$

The maritime territory of the European Union is the world's largest with an economic zone covering 25 million $\mathrm{km}^{2}$. The Atlantic Ocean, the Mediterranean Sea, the Aegean Sea, the Tyrrhenian Sea, the Adriatic Sea, and the brackish Baltic Sea can be regarded as the most important ones for the EU. If we count all economic activities that depend on the sea, then the EU's blue economy represents 5.4 million jobs and a gross added value of just under $€ 500$ billion per year. In all, $75 \%$ of Europe's external trade and $37 \%$ of trade within the $\mathrm{EU}$ is seaborne. The sea and the coasts are drivers of the economy (Blue Growth opportunities for marine and maritime sustainable growth; EU COM (2012) 494 final; DOI: 10.2771/43949).

Biodiversity in the seas is far from being fully explored. Most of the animal phyla are exclusive to biotechnological processes for selected compounds can be developed, as well as biosensors for monitoring the target compounds. The (semi) synthetic modification of marine-based bioactive compounds produces their new derivatives, structural analogs and mimetics that could serve as hit or lead compounds and be used to expand compound libraries based on marine natural products. The research innovations can be targeted for industrial product development in order to improve the growth and productivity of marine biotechnology. Marine research aims at a better understanding of environmentally conscious sourcing of marine biotechnology products and increased public awareness of marine biodiversity. Marine research is expected to offer novel marine-based lead compounds for industries and strengthen their product portfolios related to pharmaceutical, nutraceutical, cosmetic, agrochemical, food processing, material and biosensor applications.

sea environment. $\bigcirc$ Table 1 shows a classification of marine organisms exceeding 230000 known species [1], and a predicted total number of undiscovered marine species exceeds 2 million [2].

In the last decades, the attention of the natural product researchers has been focused on the marine environment: indeed, it is a wealthy source of plants, animals and micro-organisms, which due to their adaptation to this unique habitat, produce a wide variety of primary and secondary metabolites that have demonstrated significant biological activities against, e.g., cancer and inflammation, as well as in analgesia, immunomodulation, allergy, and antiviral assays. The specific habitat where an organism is growing has influence on the chemical nature of the marine primary and secondary metabolites. The intraspecific variation can produce differences in the chemical structures of compounds and their concentrations in 
Table 1 Classification of marine organisms according to Blunt and Munro [1].

\begin{tabular}{|c|c|c|c|c|c|c|}
\hline $\begin{array}{l}\text { Archaea and } \\
\text { Eubacteria }\end{array}$ & $\begin{array}{l}\text { Cyanobacteria } \\
\text { (blue-green algae) }\end{array}$ & $\begin{array}{l}\text { Chlorophyta } \\
\text { (green algae) }\end{array}$ & $\begin{array}{l}\text { Rhodophyta } \\
\text { (red algae) }\end{array}$ & $\begin{array}{l}\text { Phaeophyta } \\
\text { (brown algae) }\end{array}$ & $\begin{array}{l}\text { Bacillariophyta, } \\
\text { Chrysophyta, } \\
\text { Haptophyta }\end{array}$ & Fungi \\
\hline$\sim 1000$ & $\sim 7500$ species & $\sim 2000$ species & $\sim 6000$ species & $\sim 1500$ & $\sim 50000$ species & $\sim 1000$ \\
\hline Dinoflagellata & Porifera (sponges) & $\begin{array}{l}\text { Cnidaria (medu- } \\
\text { sae, sea anemones, } \\
\text { hydroids, corals) }\end{array}$ & $\begin{array}{l}\text { Platyhelminthes } \\
\text { (flukes, tape- } \\
\text { worms, flatworms) }\end{array}$ & $\begin{array}{l}\text { Annelida (true- } \\
\text { worms) }\end{array}$ & $\begin{array}{l}\text { Bryozoa (moss } \\
\text { animals) }\end{array}$ & $\begin{array}{l}\text { Mollusca (squid, } \\
\text { mussels, snails, } \\
\text { clams, sea hares) }\end{array}$ \\
\hline 200 species & $\sim 8000$ species & 11000 species & $\sim 18000$ species & $\sim 10000$ species & $\sim 5700$ species & 90000 species \\
\hline Echinodermata & Crustacea & Hemichordata & $\begin{array}{l}\text { Protochordata } \\
\text { (tunicates) }\end{array}$ & Pisces (fish) & Total & \\
\hline 7000 species & 60000 species & 100 species & 3000 species & 16000 species & $\begin{array}{l}\text { over } 230000 \\
\text { species }\end{array}$ & \\
\hline
\end{tabular}

Table 2 Marine or marine-derived drugs currently approved or in the pipeline. ${ }^{1}$

\begin{tabular}{|c|c|c|c|}
\hline Therapeutic class & Compound & Chemical classification & Source organism \\
\hline \multirow[t]{7}{*}{ Cancer } & Aplidine, plitidepsin (Aplidin ${ }^{\circledR}$ ) & Depsipeptide & Tunicate Aplidium alpicans \\
\hline & Brentuximab vedotin (Adcetris ${ }^{\mathrm{TM}}$ ) & Antibody-drug conjugate & $\begin{array}{l}\text { Monomethyl auristatin E, synthetic, based on } \\
\text { dolastatin } 10 \text {, sea hare Dollabella auricularial } \\
\text { cyanobacteria }\end{array}$ \\
\hline & Cytarabine, Ara-C (Cytosar-U, Depocyt) & Pyrimidine nucleoside & Sponge Cryptotheca crypta \\
\hline & Elisidepsin (Irvalec $\left.{ }^{\circledR}\right)$ & Depsipeptide & $\begin{array}{l}\text { Synthetic, based on kahalalide F, mollusc Elysic } \\
\text { rufescens }\end{array}$ \\
\hline & Eribulin mesylate (Halaven ${ }^{\circledR}$ ) & Macrolide & $\begin{array}{l}\text { Synthetic, based on halichondrin B, sponge } \\
\text { Halichondria }\end{array}$ \\
\hline & Trabectedin $\left(\right.$ Yondelis $\left.^{\circledR}\right)$ & Alkaloid & Tunicate Ecteinascidia turbinata \\
\hline & Jorumycin (Zalypsis ${ }^{\circledR}$ ) & Alkaloid & Mollusc Jorunna funebris \\
\hline Schizophrenia & DMXBA (GTS-21) anabaseine derivative & Alkaloid & $\begin{array}{l}\text { Synthetic, based on anabaseine, marine worm } \\
\text { Paranemertes peregrine }\end{array}$ \\
\hline \multirow[t]{2}{*}{ Pain } & Ziconotide (Prialt ${ }^{\circledR}$ ) & Peptide & Cone snail Conus magus \\
\hline & Tetrodotoxin $\left(\right.$ Tectin $^{\circledR}$ ) & Alkaloid & Pufferfish Tetraodontidae \\
\hline
\end{tabular}

${ }^{1}$ http://marinepharmacology.midwestern.edu/clinPipeline.htm

different marine environments [3]. It is thus essential to study different strains of the same organism from various locations. It is worth mentioning here that biodiversity in the sea can be regarded as a synonym to the chemical diversity of the marine compounds. Over 30000 compounds of marine origin are listed in The Dictionary of Marine Natural Products [1] and MarinLit database (http://pubs.rsc.org/marinlit/) at present, and about 1200 new marine compounds are reported yearly [4,5], only $5 \%$ of them having European origin. The potential of the marine environment as a source of novel drugs remains still quite unexplored.

\section{Overview of the Drugs from the Sea \\ $\nabla$}

Generally over $60 \%$ of the active principles of the pharmaceutical formulations are natural products or their synthetic derivatives or mimetics [6]. Inspection of all approved agents by FDA in the last decades clearly indicates that natural products as sources of novel structures, but not necessarily the final drug entity, are still very useful. Secondary metabolites of marine organisms are the result of millions of years of evolution and natural selection: even a single species constitutes a library of secondary metabolites that is validated for bioactivity. As a result of various enzymatic reactions, natural products have an intrinsic capacity to recognize and bind macromolecules, perturb their activity and modulate biological processes. Whereas extreme biotoxicity of some marine bioactive compounds (e.g., maitotoxin, brevetoxin B) prevent their therapeutical application, others (e.g., okadaic acid, palytoxin, fluorescent proteins from marine organisms) are used as valuable tools in cell and molecular biology or even as drugs [7].

Major pharmaceutical companies have been exploring marine compounds for several decades, but their investments and interest ceased when synthetic combinatorial compound libraries emerged since they were simpler and more cost-efficient for the high-throughput screening. However, the combinatorial chemistry approach failed to produce enough new drug entities, and in the recent years, there has been an emergence of small biotechnology companies marketing marine-based drugs [7]. Examples of approved drugs and potential therapeutic compounds derived from marine sources are given in 0 Table 2 .

- Table 2 shows that cancer is the main target for marine-derived drugs. Cytosine arabinoside or cytarabine (Ara-C; $\bullet$ Fig. 3 ) is the oldest marine drug still on market, approved by FDA in 1969. Trabectedin ( Fig. 1) has been approved by EMEA for advanced soft-tissue sarcoma in 2007 and for ovarian cancer in 2009. PharmaMar is producing trabectedin semi-synthetically from the structurally related secondary metabolite of Pseudomonas fluorescens, cyanosafracin B [8]. Eribulin mesylate was approved by FDA in 2010 for metastatic breast cancer. Antibody-drug conjugate brentuximab vedotin was approved in 2011 for relapsed Hodgkin's lymphoma and relapsed or refractory systemic anaplastic large cell lymphoma. The related monomethyl auristatin 


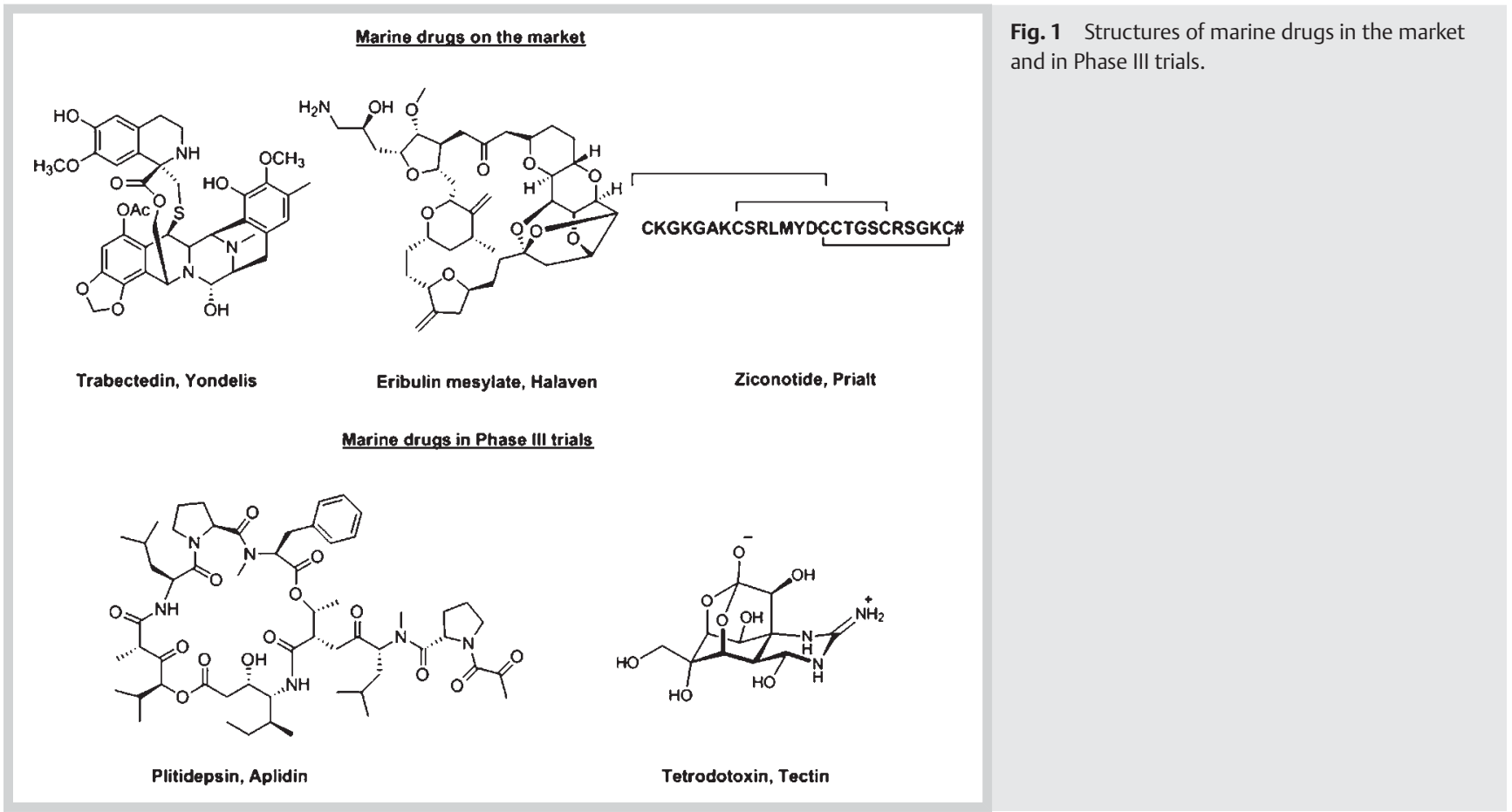

E-linked antibody drug glembatumumab vedotin (CDX-011) has completed Phase II studies for metastatic breast cancer. Potential drug candidates for multiple myeloma are aplidine and jorumycin, currently being in Phase III and Phase II trials. Conopeptide ziconotide for severe chronic pain is an exception among the cancer drugs, and another non-cancer drug in the pipeline is synthetic anabaseine-based DMXBA [9]. It is in Phase II trials for schizophrenia and Phase I for being tested for improvements in cognition.

Large scale marine biotechnology projects have been launched recently outside the EU (e.g., Norway, South Korea), but for example in the USA, institutional funding has been decreasing in the recent years [10]. In the European Union, Horizon 2020 programme is strongly investing in marine research and innovation. Its 7th Framework Programme has several ongoing marine biotechnology projects based on drug discovery: MAREX - Exploring marine resources for bioactive compounds: from discovery to sustainable production and industrial applications (20102014), BAMMBO - Sustainable production of biologically active molecules of marine based origin (2011-2014), PharmaSea - Increasing value and flow in the marine biodiscovery pipeline (2012-2016), SeaBioTech - From sea-bed to test-bed: harvesting the potential of marine microbes for industrial biotechnology (2012-2016). The earlier French programme ECIMAR studied marine chemical ecology as an indicator of biodiversity, and the projects SPECIAL and SPONGES specialized on marine sponge research as well as SWAFAX and HYFFI on seaweed bioactive compounds.

\section{Biodiversity and Ethical Aspects $\nabla$}

It is estimated that marine and coastal environments host about $90 \%$ of all organisms living on earth. The organisms play a crucial role in nutrients recycling, food provision (protein), and climate regulation. Moreover, marine organisms are unique sources of compounds used in medicine, biotechnology, agriculture, and many other branches. Despite the diverse values of biological diversity of marine organisms, life of many species has become threatened by human activities. Main pressures that result in biodiversity loss include unregulated exploitation of marine resources, overfishing, coastal development, invasive alien species, pollution, and global warming [11]. Becoming aware of the human-induced threats, many policymakers and scientists decided that a radical action should be undertaken to restore habitats and natural systems.

The overall consideration of ethical aspects of the marine biodiscovery process and product development is fundamental [12]. The key concepts in an ethical perspective in the process of translating marine biodiversity into industrial feasibility targeting innovative cosmetic, nutraceutical and pharmaceutical products are sustainability and safety. These key concepts are on both a conceptual and phenomenological level related to the concept of trust, for both building up and upholding trust in the outcome of the research and industrial processes on all levels. All key processes from the different aspects of research to evaluation of industrial feasibility and developing new products, testing, introducing and marketing them are aligned to a perspective of sustainability - and possibly gaining and up-holding trust. Upon this, also fair use of and equitable share of the benefits is included in the concept of sustainability in economic aspects. These aspects must be regulated by ethical and environmental guidelines as well as research-ethical and safety instructions. National regulative guidelines as well as international protocols (i.e., Convention of Biological Diversity) thus build a basic level of ethical decency. Researchers as well as persons on a general level are influenced by the non-human environment, mainly through different socially constructed institutions (states, political structures, laws, non-governmental organisations, public administration, etc.). The main aim of including a particular ethical perspective is two-fold: a vision of deepening understanding of the most important cultural conditions influencing the way humans tend to 
form their picture of a good life with special attention shown to the role of health as a grounded value, and how a particular research project can communicate a trust-upholding process that acknowledges and respects the role of health in people's view of life. The concept of trust is thus based on communicating sustainability also in both research-processes aiming at attaining health and with regard to environmental issues [13].

\section{Marine Organisms and Their Bioactive Compounds $\nabla$}

\section{Marine bacteria}

Marine bacteria include archaea and eubacteria, and they are an increasingly studied source for novel metabolites [4]. Archaea is an interesting group of bacteria since many of them are extremophiles, organisms that live in extreme conditions, e.g., deep sea, thermal vents, low temperature, or chemically challenging environment (salinity, pH, heavy metals). Archaean cell membranes consist of glycerol tetraethers and differ from those of eubacteria where the stabilizing element is a catenoid or hopanoid [14]. Extremophiles are a potential source not only for pharmaceutical applications but also of stable enzymes for industrial purposes [15]. Marine eubacteria consist of Gram-positive actinomycetes and bacilli, Gram-negative $\alpha$-proteobacteria and $\gamma$-proteobacteria and several anoxygenic anaerobes [14]. Marine bacteria as well as marine fungi, cyanobacteria and some microalgae are living as symbionts in sediment, sponges or other invertebrates [16]. Several marine bacteria can be grown in laboratory cultures and thus only small amounts of sample are required for cultivation, or metagenomic approaches can be used to build libraries [17].

Marine bacteria produce several classes of compounds. Salinosporamide A (marizomib) is isolated from sediment-based actinomycete Salinospora and is currently at phase II trials as proteasome inhibitor for multiple myeloma. Around 100 novel compounds (e.g., polyketides, alkaloids, fatty acids, peptides and terpenes) are isolated from marine bacteria per year [14]. Bacterial metabolites are probably the most promising source for novel antibacterial compounds since most of the natural product-derived antibacterial drugs in the pipeline are from terrestrial actinomycetes [18]. Anthracetin [19], isolated from Streptomyces species is a potential antibiotic against Bacillus anthracis and methicillin-resistant Staphylococcus aureus (MRSA). Another potential antiobiotic against MRSA and vancomycin-resistant enterococci is thiazolyl cyclic-peptide PM181104, isolated from sponge-associated actinobacterium strain of the genus Kocuria [20].

\section{Cyanobacteria}

Cyanobacteria are at the moment one of the most interesting sources of novel marine compounds [21]. Cyanobacteria have been used in medicine since as early as 1500 BC when Nostoc species were used in the treatment of gout, fistula, and cancer. Currently, cyanobacteria are the source of several products of medicinal value. These include anti-fungal, anti-inflammatory, anticancer, and anti-HIV agents [22]. 0 Fig. 2 shows the distribution of chemically different groups of compounds in cyanobacteria. It also displays the variety of biochemical activities of these compounds.

The most abundant group of cyanobacterial metabolites is that of oligopeptides derived through non-ribosomal peptide biosynthesis. Hundreds of structurally fully characterized or tentatively identified variants of cyanobacterial peptides or peptidic metab- olites have been reported [23]. Both cyclic and linear peptides are known. These can be further divided into subgroups, such as microcystins, nodularins, anabaenopeptins, aeruginosins, cyanopeptolins, etc. A common characteristic for many of the peptides is specific inhibition of various mammalian and non-mammalian enzymes. Microcystins and nodularins, strong protein phosphatase inhibitors, have been considered lethal toxins for mammals and potentially harmful for many organisms, but not enough data exist for most of the remaining compounds to enable a full bioactivity or toxicology profiling.

It was postulated that apart from morphological features, modern taxonomy of cyanobacteria should include genetic, chemical, physiological and ecological characteristics of investigated species. The application of genetic methods (only) does not reflect the morphological diversity of cyanobacterial field populations. The polyphasic classification of cyanobacteria is especially important when strains tend to change phenotypically in culture. In chemotaxonomic studies of cyanobacteria, the first classification system was based on C18 fatty acids and divided the organisms according to the number and position of double bonds in the compound [24]. Fatty acid composition quite often correlated with morphological distinctions and 165 rRNA analysis. Some researchers also used accessory pigments or aromatic amino acids in classification of cyanobacteria.

Recently, the analysis of peptides, mainly those produced by the non-ribosomal peptide synthetase pathway, was used as a new promising tool in chemotaxonomy. The diversity of cyanobacterial peptides is very high and reflects great metabolic potential of the organisms. Apart from microcystins and nodularins (the cyclic oligopeptide hepatotoxins), cyanobacteria produce anabaenopeptins, cyanopeptolins, aeruginosins, microginins and microviridins [25] and probably many other unknown peptides [26]. Characteristic feature of non-ribosomal peptides is their great variability in amino acid composition and modifications in their structure [27]. Isolated strains usually produce more than one structural variant of a given peptide. The presence of specific non-ribosomal peptides is a stable feature of individual clones; their production is independent on culture conditions, which makes them especially useful in chemotaxonomic studies. Moreover, some of the compounds show biological activity, strongly depending on modifications in their chemical structure. Tandem mass spectrometry with sensitive detector (e.g., time of flight, TOF) is useful to find individual peptides or to determine peptide fingerprint characteristics for a clone or closely related clones of cyanobacteria producing bioactive compounds [28].

\section{Microalgae including dinoflagellates}

Microalgae play an important role in marine biological ecosystems, because of their photosynthetic activity. They are the major producers of biomass and organic compounds in the oceans. Marine microalgae are separated into five major divisions: Chlorophyta (green algae); Chrysophyta (golden-brown, yellow algae, and diatoms); Pyrrhophyta (dinoflagellates); Euglenophyta, and Cyanophyta (blue-green algae). The last division, Cyanophyta, is widely classified and its organisms termed as cyanobacteria and not included in the category of algae, because of their prokaryotic characteristics, despite the fact that the organisms are photosynthetic and share many algal characteristics with their eukaryotic counterparts [29]. The microscopic planktonic algae in the oceans are crucial food for filter-feeding bivalve shellfish (oysters, mussels, scallops, clams, etc.) as well as the larvae of commercially important crustaceans. In most cases, the proliferation of 


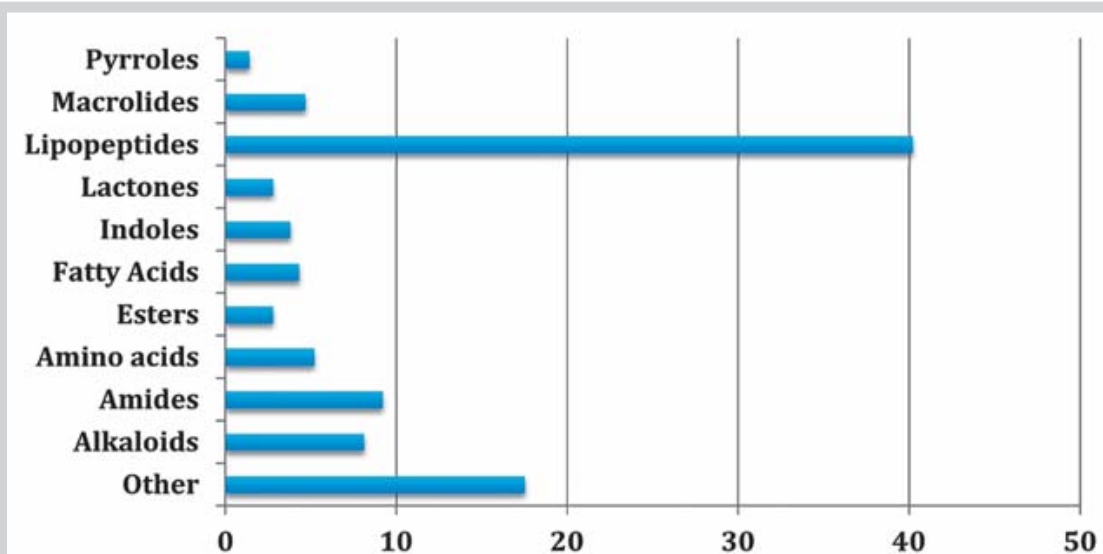

Fig. 2 An example of: A distribution of chemical classes of compounds in cyanobacteria and $\mathbf{B}$ their therapeutic classes [22]. (Color figure available online only.)

A

$\%$ Distribution of chemically different groups of compounds in cyanobacteria

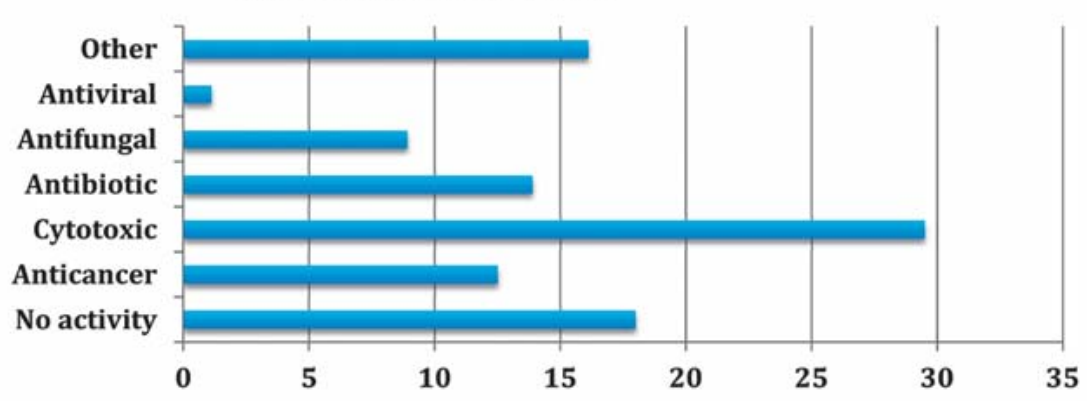

B

$\%$ Biological activity of 424 marine cyanobacterial compounds

planktonic algae (up to millions of cells per litre) is beneficial to aquaculture; but in some situations, it can have a negative effect, causing economic losses and having major environmental and human health impacts. Among marine phytoplankton, about 300 species of dinoflagellates can sometimes proliferate in such numbers that they discolour the surface of the sea, the so-called red tides and brown tide phenomena. About 40 of these species have the capacity to produce potent toxins that can find their way through fish and shellfish to humans [30]. Harmful algal blooms can be classified into three major groups. The first is formed by non-toxic species whose proliferation under anoxic conditions results in indiscriminate killing of both fish and invertebrates. Examples of dinoflagellates that cause these problems are Gonyaulax, Noctiluca, and Scrippsiella. A second group, recently recognised as a result of the increased interest in intensive aquaculture systems, is characterized by some algal species that can seriously damage fish gills, either mechanically or through production of hemolytic substances. Examples of dinoflagellates of this group are Prymnesium parvum, Amphidinium carteri, Chrysochromulina polylepis, Heterosigma carterae etc. Finally, a third group is integrated by those species which produce potent toxins which can find their way through the food chain to humans, causing a variety of gastrointestinal and neurological illnesses. According to the symptoms observed in human intoxications, it is possible to consider five groups of marine toxins; PSP: paralytic shellfish poisoning (Alexandrium, Gymnodinium and $P y$ rodinium species); CFP: ciguatera fish poisoning (Gambierdiscus toxicus, ciguatoxin and maitotoxin); DSP: diarrhetic shellfish poisoning (Dinophysis and Prorocentrum species, yessotoxin, pecte- notoxins and okadaic acid); NSP: neurotoxic shellfish poisoning (Gymnodinium breve, brevetoxins); ASP: amnesic shellfish poisoning (Pseudonitzschia species, domoic acid); and AZP: azaspiracid poisoning (Azadinium spinosum, azaspiracid). Dinoflagellates produce also nitrogen-containing toxins, e.g., large zooanthellatoxins and smaller saxitoxins (PSP), but smaller secondary metabolites, e.g., sterols, being a minority. Dinoflagellate toxins are being used as tools for studying cellular processes, but they have not reached the clinical studies despite promising bioactivity results. Structure determination of these extremely complex natural products requires advanced NMR techniques, and total synthesis of, e.g., maitotoxin (32 rings, 98 stereocenters), is far from being finalised and may still affect to the original assignment [31].

\section{Macroalgae}

Marine macroalgae, or seaweeds, have been used as sea vegetables, medicines, and fertilizers for centuries. Natural products extracted from seaweeds include the gelling polysaccharides agar and carrageenan (extracted from the Rhodophyta) and alginate (from members of the Phaeophyta); sometimes these are referred to as hydrocolloids or phycocolloids. The food industry exploits the gelling, water-retention, emulsifying and other physical properties of these hydrocolloids. In the biomedicine and pharmaceutical industries, alginates are used in wound dressings, production of moulds, tissue engineering, and drug delivery systems, and have a host of other applications. Carrageenans, alginates, and agaroses (the latter are prepared from agar by purification) also have several important biological activities or appli- 

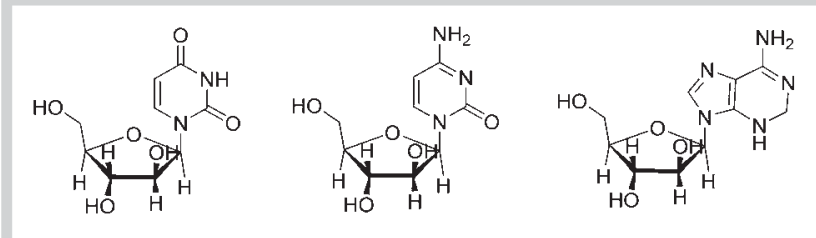

Cytarabine, Ara-C

Viderabine, Ara-A

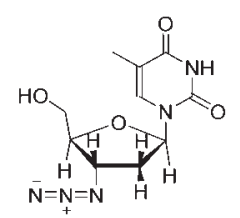

Fig. 3 Drugs derived from spongouridine (Tectitethya crypta). cations in biomedicine. A large number of anticoagulant polysaccharides from marine algae have been isolated and characterized. They exert their anticoagulant activity through potentiating antithrombin III (AT III) and/or heparin cofactor II (HC II). The anticoagulant mechanism is the one by which heparin, heparin sulfate, and dermatan sulfate exert their activity. On the other hand, some algal anticoagulant polysaccharides exert anticoagulant activity through directly inhibiting fibrin polymerization and/or thrombin activity without potentiating AT III and HC II. Furthermore, new functions of algal polysaccharides have been discovered recently, as it has been shown that heparin and its derivatives have important roles in many biological processes. Algal anticoagulant polysaccharides also activate fibrinolysis system, modulate endothelial cell functions and possess anti-platelet activity [32]. Novel anticoagulant compounds have been recently isolated from fermented red alga Pachymeniopsis elliptica [33] and red seaweed Lomentaria catenata [34].

Marine organisms use chemical compounds to solve problems which also humans face. Relevant examples here are antifouling and UV sunscreen compounds [35]. Many intertidal seaweeds are exposed to dangerous levels of high-energy radiation that could overload their photosystems or cause damage to proteins and DNA; humans face a similar problem. Seaweeds are constantly faced with microbes, spores and invertebrate larvae that attempt to settle on the thallus surface; similarly, submerged man-made structures such as ships' hulls also form attractive surfaces for settlement. The mechanisms algae employ to overcome these problems (fouling, photodamage) can also be adapted for human use, resulting in new technologies (natural antifoulants, novel UV sunscreens). It is clear that investigations of appropriate natural models can provide an efficient way for the discovery and development of useful metabolites.

\section{Marine fungi}

Marine fungi belong to phyla Chytridiomycota, Oomycota, Ascomycota, Bacidomycota, Deuteromycota, and Zygomycota [14]. Like marine bacteria, marine fungi often live as symbionts in algae or marine invertebrates, especially sponges. Collection of marine fungi usually requires the collection of the host or supporting material (e.g., algae, marine invertebrates, sediment or water), which gives challenges to maintain the viability until extraction [36]. Most of the fungal species isolated from sponges belong to the genera Aspergillus and Penicillium. Around 150200 new compounds are now isolated from marine fungi yearly [4], and the number has been increasing. The compound classes include polyketides, sesquiterpenes, alkaloids, or aromatic compounds. Although no marine fungus-based drug is currently in the pipeline, promising cytotoxic, neuroactive, antibacterial, antiviral, and antifungal activities have been found from fungi metabolites.

\section{Marine invertebrates}

Sponges (Porifera): As can be seen from $\bigcirc$ Table 2, sponges are a potential source for marine-derived drugs including eribulin mesylate, Ara-C, and discodermolide. The history starts with the discovery and subsequent identification of spongothymidine and spongouridine in 1951 from the Caribbean sponge Tectitethya crypta (formerly known as Cryptotethia crypta) [37]. Drugs developed from nucleoside spongouridine are Ara-C ( $\bullet$ Fig. 3 ), viderabine (or adenine arabinoside, Ara-A), an antiviral compound approved by FDA (U.S. Food and Drug Administration) in 1976 but not currently on the market, and zidovudine (or azidothymidine, AZT), one of the most popular anti-AIDS agents. The so-called pharmacodiversity can be considered to be the most substantial in sponge derived compounds [14].

Very recently sponge molecular systematics has become an alternative to morphological characterization, because the number of new sponge metabolites (297 in 2011 and 355 in 2012 [4]) increases constantly, and their structural complexity hints at a large source of new genus-specific characteristics. Presence (or absence) of a particular compound or compound family among different sponge taxa may indicate a closer phylogenetic relationship. Compound classes of sponge metabolites include terpenes, sterols, fatty acids, cyclic peptides, amino acid derivatives, nucleosides, peroxides, and alkaloids, also bromine-containing compounds are common. Another problem in chemotaxonomy is the correct assignment of a compound as sponge- and not associate-derived. When the high abundance of symbionts in sponges was discovered, it was demonstrated that sponge microsymbionts may also be the source of some of the bioactive compounds. Numerous substances bear remarkable structural similarities to bacterial compounds, implying a bacterial origin despite their high complexity.

Tunicates: Tunicates are the origin of two marine-based drugs, trabectedin and aplidine. Tunicates can be divided in three classes: ascidians (sea squirts, sea tulips), thaliaceans, and appendicularians, together comprising over 3000 species [38]. The first chemical compound directly from a marine source to enter clinical trials in 1980 was didemnin B, an anticancer agent isolated from the tunicate Trididemnum solidum. Although didemnin B was not successful due to its toxicity, this discovery paved the way to finding several new marine metabolites with anticancer properties. Tunicates produce structurally variable metabolites, and around 40 new structures are found yearly including macrolides, terpenes, alkaloids, and brominated aromatics [4].

Cone snails: Contrary to a common misbelief which may have discouraged some attempts of their sustainable synthetic production, not all marine bioactive compounds possess very complex chemical structures. Nowhere is the diversity of bioactive peptides more apparent than within the small peptides (conotoxins and conopeptides) present in the venom of cone snails, a family of widely distributed marine molluscs. These peptides have 
evolved in $~ 500$ species of fish-, mollusc- and worm-hunting cone snails for rapid prey immobilization and defence. Their small size, relative ease of synthesis, structural stability and target specificity make them important pharmacological probes. $\mathrm{Zi}$ conotide, a 25-residue peptide, originally isolated from Conus magus, is marketed for neuropathic pain under the name of Prialt $^{\circledR}$. It is estimated that over 50000 conopeptides exist, but $<0.1 \%$ have been characterized pharmacologically [39]. This area offers a huge opportunity for peptide-derived therapeutics employing the principles of peptidomimetics design. An orally active peptide for the treatment of neuropathic pain has been engineered from conotoxin [40]. Cone snails are one of the key organisms to be studied in various electrophysiological studies as a source of valuable new compounds.

Cnidarians: These organisms are incredibly diverse in form, and their five major groups are Anthozoa, which includes true corals, anemones, and sea pens; Cubozoa, the box jellies with potent toxins; Hydrozoa, the most diverse group with siphonophores, hydroids, fire corals, and many medusae; Scyphozoa, the true jellyfish and Staurozoa, stalked jellyfishes [41]. Yet, these diverse animals are all armed with stinging cells called nematocysts. Cnidarians are united based on the presumption that their nematocysts have been inherited from a single common ancestor [42]. Over 3000 compounds have been isolated from cnidarians in the last decade, and the majority of them are terpenoids. Sea anemones produce also fluorescent pigments, zoanthoxantins, and polypeptide toxins affecting voltage-gated ion channels.

\section{Marine fishes}

Fishes are a diverse group of living vertebrates with more than 27000 species currently known, and over 16000 of them are marine species [43]. Fish-based $\Omega$-3 fatty acid ethyl esters are registered as a drug named Lovaza ${ }^{\circledR}$ in the USA or Omacor ${ }^{\circledR}$ in the EU; currently, it is the only fish-oil product approved as a drug. Oil from fresh livers of cod, Gadus morrhua, and from halibut, Hippoglossus hippoglossus, is used in vitamin A and D therapy. Squalene, present in large quantities in shark liver oil and also in plant kingdom, e.g., in olives, is used as antimicrobial, immune system enhancer, and as an intermediate in the manufacture of pharmaceuticals and an adjuvant in the vaccines [44]. Tetrodotoxin, one of the most toxic low molecular weight poisons is produced by symbiotic bacteria and is found in certain puffers, ocean sunfishes, and porcupine fishes. Tetrodotoxin is also unique in preventing the usual increase in permeability to sodium ions without affecting the outward potassium flow, and it has potential for the treatment of neuropathic pain currently in Phase III trials [45].

\section{Cultivation and Sustainable Collection Methods}

$\nabla$

\section{Isolation of cyanobacteria and microalgae}

Maintaining pure cultures using preservation methods is of high importance for biotechnological purposes [46]. The first step toward successful isolation is understanding and mimicking the naturally occurring environmental conditions [47]. In addition, taxonomic knowledge of the target species is very important. The second step toward successful isolation involves the elimination of contaminants, especially those that can out-compete the target species. Natural samples often contain zooplankton feeding upon algae, which can quickly consume or otherwise kill algae. Timing is of essence; some organisms die quickly, even with- in one hour or a few hours after sampling. When samples are enriched some species quickly multiply but die suddenly, demonstrating a different aspect of timing. Application of good sterile technique is also crucial, as well as selection of proper culture medium with correct nutrient concentrations. Therefore, before isolation of cells begins, serious attention should be paid to the culture medium or media that will be used. Single cells of common weedy organisms (e.g., Chlorella-like organisms, Tetraselmis, and many diatoms) grow well when placed directly into fullstrength medium.

To ensure the successful isolation of collected cyanobacteria and microalgae, state-of-the-art isolation methods must be used. For example, enrichment cultures can be established by adding enriching nutrients (culture medium, soilwater extract, or macronutrients, i.e., nitrate, ammonium, and phosphate) to the natural sample, which increases the algal growth. Single-cell isolation by micropipette can be used to remove other small cells, leaving the target organism free of contamination. On the other hand, isolation by using agar-streaking cells across agar plates is the preferred choice for many coccoid algae. Agar pour plates may need to be used in case the algae do not grow on the surface of agar plates but do grow embedded in agar (e.g., oceanic picoplankton). Isolation of microalgae may also be assisted by dragging through agar (e.g., shearing epiphytes from the filament), dilution techniques, gravity separation, atomic cell spray or by the use of phototaxis (used for example in isolation of flagellates).

\section{Isolation and purification techniques for long-term macroalgal culture maintenance}

Macroalgae is a general term for the algae that form a multicellular thallus at least in one stage of the life history, with the exception of siphonous ulvophycean algae that lack septa (e.g., Caulerpa and Valonia). In most cases they show differentiation between vegetative tissues and reproductive structures that release unicellular reproductive cells, as well as an alternation of generations. Therefore, to observe the development from unicellular reproductive cells to multicellular thallus, or to elucidate the whole life history that often cannot be observed from field-collected specimens, culture studies are necessary. Unialgal, clonal, and axenic cultures of macroalgae have become essential for studies of morphogenesis, morphological development, nutritional physiology, responses to various chemicals, crossing experiments, extracting various compounds without contamination (genomic DNA, cDNA libraries, Northern blotting, etc.), long-term strain preservation, exchange of research materials, mass culture and preparation of mariculture seed-stock. A unialgal culture is a culture that includes only one species of alga (bacteria may be present). An axenic culture is unialgal and free of bacteria. A clonal culture is a culture of a single genome set (e.g., cultures derived from a single vegetative cell or tissue or from a reproductive cell) and propagated vegetatively.

\section{Sustainable biotechnological production}

The successful search for bioactive compounds and substances is directly correlated to the increasing numbers of species being brought into culture [48]. Only the controlled maintenance of marine organisms makes their sustainable exploitation for industrial purposes possible. Many photosynthetic organisms also exhibit heterotrophic growth when nutrients are available in the absence of light. Since the profile of bioactive compounds produced may be influenced by the mode of nutrition, biomass of organisms of particular interest will be produced autotrophically, 
heterotrophically, and mixotrophically (growth in which nutrients are obtained both photosynthetically and heterotrophically) so that the product profiles can be determined under each condition. Heterotrophic cultures offer the advantages of easier scale up and higher potential biomass densities than photosynthetic cultures and thus may be desirable for the production of high-value bioactive compounds. For example, most photosynthetic cultures only achieve biomass densities in the range of $1-5 \mathrm{~g} \cdot \mathrm{L}^{-1}$, whereas heterotrophic cultures may achieve biomass densities greater than $50 \mathrm{~g} \cdot \mathrm{L}^{-1}$ [49]. The productivity of microbial cultures is often improved by growing the producing organism in high cell density fed-batch culture rather than batch cultures. High cell density fed-batch cultures may be relevant for some heterotrophically produced algal compounds [50], but are not practical for photosynthetic cultures. Continuous flow culture systems can be used to improve productivity of both photo- and heterotrophic cultures.

\section{Extraction, Separation, Isolation, and Purification of Marine Compounds \\ $\nabla$}

The freeze-dried marine organisms are soaked in a solvent of medium polarity. The solvents of choice are methanol and acetone. Crude extracts from marine organisms often contain complex mixtures of a number of compounds that need several sequential purification steps. Usually the first step is a liquid solvent partitioning procedure. One of the most used is the Kupchan [51] procedure that uses solvents with increasing polarity, affording enriched extracts. MPLC on different stationary phases (adsorption chromatography with silica gel, or reverse phase chromatography with octadecylsilyl (RP8) or octylsilyl (RP18) chain phases) and exclusion chromatography on, e.g., LH-20 and LH-60 supports are effective for a first-stage fractionation. Liquid-liquid chromatography without supported stationary phases such as droplet countercurrent chromatography and centrifugal partitioning chromatography are very efficient in assuring a good level of purification of polar extracts with a complete recovery of the material, avoiding the problem of the irreversible adsorption experienced when traditional supported stationary phases are used. The last step of purification is done by HPLC, which allows obtaining compounds with a high degree of purity.

\section{Advanced Spectroscopic Methods of Structural Determination, Stereochemical Characterization, and Chemotyping \\ $\nabla$}

Mass spectrometry with new ionization techniques coupled with liquid or gas chromatography enables high-precision analysis of marine biomolecules and fingerprinting of fractions. Rapid first chemotyping of the studied biological materials and substances is essential for de-replication, the major bottleneck in the search of novel marine natural products. MS data can also be utilized in development of metagenomic methods for discovering marine natural products and their biosynthetic pathways [52].

With the advent of high field spectrometers and inverse decoupled heteronuclear correlation techniques, NMR spectroscopy has become a practical alternative to X-ray crystallography for the structure elucidation of natural products [53]. Currently, all but the most complex organic molecules are amenable to routine analysis, even with submilligram sample quantities. The struc- tural elucidation of complex molecules by modern NMR methods is particularly useful in the natural products field, as natural products are often isolated in small amounts and do not easily crystallize. Therefore, approaches relying on "non-invasive" spectroscopic and spectrometric analysis of intact compounds are extremely appealing in this context, allowing the sample under investigation to be used for further pharmacological evaluation. Further, NMR and other spectroscopic techniques allow the sample to be preserved for further investigation.

As part of the complete structural elucidation of natural products, the determination of relative and absolute configuration is undoubtedly a key step. In fact, the full topology of the molecule has a profound impact on its biological and pharmacological properties. Nowadays several methods, mainly relying on NMR and computational approaches have provided a reliable access to the configurational assignment of even complex and flexible molecules [54]. In particular, J-based configuration analysis is a powerful yet simple technique for determining stereochemistry and conformation of a molecule [55]. Several instrumental methods exist for the determination of absolute configuration. Chirooptical methods (e.g., circular dichroism (CD), infrared (IR) and UV spectroscopy will also give structural information [56]. All of these techniques must be utilized to obtain and guarantee high-quality structural information of the isolated and purified bioactive marine compounds.

\section{Technologies for Exploring the Bioactivity Potential of Natural Products \\ $\nabla$}

Exploring large chemical libraries for biological activity is typically carried out through high-throughput screening (HTS) campaigns, which enable the study of thousands of samples in a short time-span. HTS assays can be configured to study biological responses from isolated biochemical systems containing purified receptors or enzymes, to signal transduction pathways and complex networks functioning in cellular environments. HTS is originally industry-driven technology, but in the recent past, academic input within this research field has significantly increased. This has led to innovations for improving HTS methodologies, especially in developing advanced cell-based, phenotypic screening models, which have recently been considered as key factors in improving the success of modern drug discovery [57,58]. Many of these models employ so-called high-content screening (HCS) technologies, i.e., automated platforms enabling cellular imaging and quantitative image analysis in high-throughput format. Initially, HCS was mostly used in follow-up studies for hits identified in biochemical HTS campaigns, but due to technological advances the use of HCS in the early stages of drug discovery has expanded [59]. By using HCS as an initial screening tool, the sample libraries can be studied directly in complex cellular environment, which is considered to provide more predictive, physiologically relevant information compared to target-based approaches [60,61].

The success of any bioactivity screening campaign is dependent on the quality of the chemical library to be screened. Historically, natural products (NPs) have constituted a rich source of lead molecules in drug discovery, but de-emphasised in industrial screening campaigns mainly due to difficulties in obtaining high-quality NP libraries suitable for large scale HTS [62]. These libraries can contain a variety of different sample types, such as crude extracts, semi-pure fractions, or purified natural compounds, which make them a challenging source for HTS. When 
designing the library, advantages and disadvantages of each of these categories need to be carefully evaluated. Preparation of crude extract libraries is usually economical but demands extensive resources for later identification of bioactive components. Constructing a library based on semi-pure fractions or purified natural compounds is costly and labour-consuming but may reduce interferences encountered typically with crude extracts in HTS and also simplify the detection of actives. However, recent technological advancements made in constructing NP libraries and in follow-up studies have facilitated the use of NPs in screening campaigns. Generating a large-scale marine NP library amenable to HTS and shortening the identification of active compounds have been pursued, for example, by coupling online characterisation by MS into the process [63]. Efficient dereplication strategy (i.e., identification of previously known components) is also essential and should be implemented as early as possible in the process. This can be pursued by using metabolic profiling as a tool to evaluate the diversity and novelty of compounds present in the NPs $[64,65]$.

\section{Synthetic Modification of the Marine Bioactive Compounds}

Natural compound libraries have always been an excellent source towards new drug candidates. Marine bioactive compounds can have a greater number of asymmetric atoms and increased steric complexity than any of the synthetic drugs. Natural products contain unique ring systems. Surprisingly, less than $20 \%$ of these diverse structural scaffolds are present in the current drugs on the market [66]. Interestingly, the fraction of natural compound structures with two or more "Lipinski-rule-of-five" violations is only about $10 \%$ and equal to that of the commercialised drugs. These complex structures offer challenges to synthetic chemists, but often the scope is primarily directed to the synthesis and optimization of more simple drug-like structures (MW preferably $<500$ Dalton). Despite numerous brilliant examples of total synthesis of marine compounds $[67,68]$, it is often possible and reasonable to define the crucial structural elements required for biological activity. The methods of medicinal chemistry are useful in designing and synthesising structurally simple, potent and selective compounds with feasible and sustainable synthetic routes and at reasonable cost. The synthetic compound libraries often tend to exclude complex chemical structures although a diversity-oriented synthesis approach can lead towards more natural compound-like structures [69].

\section{Industrial Applications of Marine Bioactive Compounds \\ $\nabla$}

\section{Pharmaceutical applications}

Inflammation and cancer: Although the association between inflammation and cancer has long been suspected [70], the precise mechanism of inflammation-induced malignant transformation is not fully understood. Chronic inflammation is characterized by an ongoing and sustained release of reactive oxygen and nitrogen species and of pro- and anti-inflammatory cytokines and chemokines [71]. Such inflammatory mediators are considered as major pathogenetic factors of carcinogenic malignant transformation of human intestinal epithelial cells during chronic inflammatory diseases (i.e., ulcerative colitis). Epigenetic changes have emerged as one of the most consistent molecular alterations in various neoplasms and have been implicated in mechanisms of cancer progression such as DNA damage and repair, apoptosis, and cell cycle control. Recently, a molecular link between inflammation and cancer has been made through the implication of NF$\kappa \mathrm{B}$ in promoting the cellular changes leading to uncontrolled growth of cancer cells by antagonizing pathways of cell death and later on changes that help tumor progression and metastasis [72]. Moreover, tumor cells produce COX-2 (cyclooxygenase, a pro-inflammatory macromolecule) that gives a further boost to inflammatory processes making the link between cancer and inflammation very interactive $[73,74]$. Hence, therapeutic agents with anti-inflammatory effects could be of great benefit to inhibit cancer growth and spread $[75,76]$.

Ion channels: The demonstrated implication of ion channels in physiological phenomena such as neuronal excitation, excitation-contraction coupling or stimulation-secretion coupling makes it not surprising that a number of organisms have developed channel-specific toxins as mechanisms for self-defence or for capturing prey. A rich, non-exhaustive collection of natural toxins selectively target the ion channels of neurons and other cells and represent valuable tools for studying the function of cellular ion channels. One of the best-known channel toxins is tetrodotoxin [77], currently in Phase III trials for cancer-related pain. It elicits a potent and specific block of some subtypes of voltagegated $\mathrm{Na}^{+}$channels responsible for action potential generation, thereby paralyzing the animals that ingest it. Ziconitide, a potent conotoxin that induces significant analgesia when delivered spinally, is a rare toxin-based commercially available drug [78]. This neuronal-specific, $\mathrm{N}$-gated calcium channel blocker works at the dorsal horn and is effective in a variety of pain states. The mechanisms of action for conotoxins are further studied [79]. Despite a growing interest, the use of toxins for developing drug leads is still a niche research area.

Antimicrobial and antiviral applications: Discovery of new antimicrobial agents and characterisation of the mechanisms of action for potential leads are essential issues for modern pharmaceutical research. Today the market size for antimicrobials is huge, but the increasing number of emerging resistant bacterial strains is becoming a limiting factor in the usefulness of current drugs available. However, antimicrobial drug discovery has become highly unattractive to pharmaceutical companies mainly due to short antibacterial drug lifecycles and the acute, rather than chronic, nature of antibacterial therapy [80]. As a result, new classes of antibiotics are nowadays hardly discovered. Marine natural products have a great potential for antimicrobial applications but NP-based antibiotics in the pipeline still originate from fungi or actinomycetes [18]. One very important subcategory in antimicrobial therapy is antiviral drugs, where the availability of specific clinical treatments is still very limited. Yet, viruses are widely recognised as emerging sources of new epidemics. For example, insect-borne alphaviruses are currently spreading to more northern areas, which has been demonstrated by the spread of West Nile virus in the USA [81], and even more recently by the outbreaks of chikungunya virus in the Indian Ocean region and in Italy $[82,83]$. In Finland, strains of Sindbis virus cause tickborne encephalitis and Pogosta disease [84]. Alphaviruses are positive-strand RNA viruses and belong to the largest group of viral pathogens containing several major pathogens, such as hepatitis A, C and E viruses, rhinoviruses (major cause of common cold), coronaviruses (common cold and severe acute respiratory syndrome, SARS), and alphaviruses (Sindbis, chikungunya, 
dengue fever, yellow fever, West Nile virus encephalitis, Semliki Forest), which share certain antigenic determinants. Despite their wide distribution and potential pathogenicity, neither effective chemotherapy nor commercial vaccination is available for clinical alphavirus infections.

\section{Cosmetics}

A classic example of marine compounds in cosmetic products is Estée Lauder's Resilience ${ }^{\circledR}$ that contains anti-inflammatory pseudopterosins from soft coral Pseudopterogorgia elisabethae [85]. The effects of harvesting of the soft corals have been studied, and it is an excellent example of sustainable exploitation of marine organisms. Clipped soft corals were branching and growing even faster than the control group [86]. Pseudopterosin A has even potential as a drug since it has been in Phase II trials as topical anti-inflammatory agent. Marine anti-inflammatory compounds will also have potential use in cosmetics, and there is an unmet need of new UV-absorbing and sustainable compounds for sunscreen applications to replace the currently used allergenic, irritating, or bioaccumulative sunscreen agents.

\section{Nutraceuticals}

Fish oils, omega-fatty acids, and marine lipids are probably the best known marine food supplements. Even one omega-3 fish oil product, Lovaza ${ }^{\circledR}$, has been approved as a drug by FDA. Only few species (e.g., Chlorella vulgaris and Spirulina pacifera) from 40000 species of algae have been used by the food industry [87]. Microalgae contain carotenoids, sterols, lipids, and polyphenols. Carotenoids have been produced in large scale in photobioreactors. Anti-oxidant and food dye astaxanthin can be produced effectively from Haematococcus biomass [88]

\section{Biosensors}

Marine biotoxins are chemical compounds that can be classified according to the acute symptoms that they present to humans and other mammals when ingested with contaminated seafood. Food safety in marine resources is especially important because of the unseen threat of microalgae. More specifically, several species of dinoflagellates and diatoms produce odorless and tasteless phycotoxins, which enter the food chain through shellfish and several other marine carnivores [89]. Syndromes caused by phycotoxins range from diarrhea, vomiting and spasms to even coma and death. Traditionally, these toxins have been detected in seafood using laborious biological and animal reference methods. The release of the European Union Directive 86/609 for animal protection to ensure progress away from animal experimentation to scientifically acceptable validated non-animal procedures started the scientific exploration for alternative methods for these animal bioassays [90,91]. Biosensor technologies are analytical tools for the recognition and measurement of a target through its association with a biological component and physiochemical detector. Therefore, a biosensor typically consists of a bio-recognition element, transducer, and an electronic system composed of a signal amplifier, processor, and display. Today, biosensors are widely known and appreciated for sensing purposes in a wide range of analytical applications [92]. The most prominent receptor molecules used are enzymes, antibodies, and aptamers [93]. Their interaction with the target of interest is converted to a measurable signal. Biosensor technology also benefits from fast growing disciplines such as micro-electronics, which results in advanced biochips by combining the knowledge of microfluidics with microelectronics [94]. Until today, various phy- cotoxin biosensors have been made. The most common are based on antibodies and enzymes. For example, Marquette et al. developed an immunosensor for okadaic acid integrated in a fiber optic-based chemiluminescence flow injection system [95-97]. Palytoxin is a polyether marine toxin originally isolated from the zoanthid Palythoa toxica and is one of the most toxic nonprotein substances known. Fatal poisonings have been linked to ingestion of contaminated seafood. Its co-occurrence with other well-characterized seafood toxins (e.g., ciguatoxins) has hindered its direct associations to seafood-borne illnesses. A new Biacore T100 SPR assay for palytoxin using an anti-mouse substrate to characterize the kinetic values for a previously developed monoclonal antibody raised to palytoxin has been developed [98]. Tissue-based biolectronic sensors have also been developed: paralytic toxins were detected by investigating their effect as sodium channel blockers [99].

\section{Agricultural applications: plant growth regulators,} herbicides, and biocides

Cyanobacterial or macroalgal extracts may have use in agriculture as plant growth regulating agents, fertilizers, and as agents increasing nutrient uptake from soil or improving plant resistance. Additionally, freshwater cyanobacteria have been studied for their potential use as algal growth inhibitors. Most of the cyanobacterial herbicides inhibit electron transport in the vicinity of photosystem II. The effect of cyanobacterial extracts on photosynthesis, growth and development of higher plants and algae is worth examining. The potential use of the extracts or isolated compounds as plant growth regulating agents is useful to be assessed.

There are reports showing that algal extracts can be used in agriculture as agents increasing crops by stimulating growth, increasing nutrient uptake from soil or improving plant resistance to infections and unfavourable weather conditions. Commercial extracts made from brown alga (Maxicrop, Kelpak, Goemar, Seasol, and Algifert) have been applied to crop lands for improving yields and plant vigour. The extract from unicellular green alga Chlorella has been shown to stimulate chlorophyll synthesis and growth of shoots and roots of fruit-trees, vegetables, and rice. Chlorella extract has been approved in Japan as a growth-regulating agent. Cyanobacteria, the most dominant photosynthetic prokaryotic microorganisms, are also known to produce compounds that potentially could be used as fertilizers and plant growth regulating agents. Their beneficial effect on plants (rice and wheat) was originally attributed to nitrogen fixation. Later it was postulated that the positive influence of cyanobacteria on seed germination and growth is additionally induced by the presence of vitamins and plant hormones or compounds with plant hormone-like activity. Effects attributed to this type of activity were detected among others in Calothrix sp., Hapalosiphon intricatus, Nostoc sp., and Arthronema africanum [100,101].

On the other hand, some cyanobacteria, e.g., of the genera $\mathrm{Fi}$ scherella, Scytonema, Nostoc, Hapalosiphon, and Oscillatoria, were found to produce compounds of algicidal activity directed against photosynthesis. Most of these natural herbicides inhibit electron transport in the vicinity of photosystem II. Other effects include inhibition of RNA synthesis and DNA replication. Cyanobacterial toxins are known to inhibit growth of a range of terrestrial plants; toxin uptake was correlated with lipid peroxidation in seedlings [102]. In some instances, the metabolites produced by cyanobacteria could replace synthetic phyto-regulators, toxic to non-target organisms [103]. Furthermore, the role of the compounds in 
allelopathic interactions and functioning of aquatic ecosystem has been discussed [104].

Another interesting phylum is Porifera and, for example, metabolites from marine sponges may provide a promising alternative to the use of ecotoxic heavy metals in antifouling coatings. Water-soluble polymeric 3-alkylpyridinium salts isolated from the Mediterranean sponge Reniera sarai and 14 related synthetic analogs have shown considerable antibacterial activity against marine biofilm bacteria and may represent good candidates as natural biocides for marine technology applications $[105,106]$. It has also been shown that barettin and dehydrobarettin, diketopiperazines isolated from the marine sponge Geodia barretti, are potent inhibitors of barnacle larvae settlement $[107,108]$.

\section{Biofilms}

A biofilm is any group of microorganisms in which cells stick to each other on a surface. These adherent cells are frequently embedded within a self-produced matrix of extracellular polymeric substance (EPS). Biofilm extracellular polymeric substance is a polymeric conglomeration generally composed of extracellular DNA, proteins, and polysaccharides. Biofilms may form on living or non-living surfaces and can be prevalent in natural, industrial, and hospital settings $[109,110]$. Among bacteria, only a little is known about chemical defense against bacterivorous consumers. According to one hypothesis, sessile bacterial communities organized as biofilms serve as bacterial refuge from predation. By testing growth and survival of common bacterivorous nanoflagellates, evidence has been found that chemical mediated resistance against protozoan predators is common among biofilm populations in a diverse set of marine bacteria [111]. Chemical communication is essential in biofilm populations to coordinate their behavior and respond to environmental pressure. Recent research has been unravelling a complex web of chemical crosstalk mediating microbial symbiosis, competition and defense against predators and pathogens. When the molecular basis of biofilm interactions in their ecological context is understood, the potential of natural product discovery and the development of biofilm-derived biotechnologies are achievable [112].

There are certainly natural products to be found with interesting activities in antimicrobial, especially in anti-biofilm, research. Biofilms are surface-attached bacterial communities embedded in a self-produced matrix, making them much more resistant in comparison to their planktonic counterparts. The unique properties of bacterial biofilms call for the development of reliable and specific research methods, different to the ones optimized for planktonic bacteria. To fill the void of biofilm assays suitable for NP screening, a statistically robust platform of assays was developed by Skogman et al. [113]. Three important features of biofilms were targeted using three separate assays ran in sequence after each other. The effect the tested compounds have on biomass and viability can be studied at a primary screening stage. This is followed by investigating the effect the compounds have on the EPS-layer at a secondary screening stage. Hereby only so called true hits are found. This platform has been further used for a library of flavonoids [114], and also small molecule peptides [115], thus paving the way for many other natural products. Pharmaceutical, paper and pulp, and biofouling industries will benefit in future via finding new anti-biofilm compounds as the biofilm matrices are resistant for chemical agents of today.

\section{Conclusions}

\section{$\nabla$}

The marine environment is a rich source of biological and chemical diversity. This diversity is the source of novel chemical compounds with the potential for industrial applications as pharmaceuticals, cosmetics, nutritional supplements, molecular probes, fine chemicals, and agrichemicals. The oceans represent an untapped resource for discovery of new compounds with useful activity. Although the future potential of marine biotechnology relates to the discovery, development, and sustainable use of marine-derived compounds with health promoting applications, the needs, approaches, and opportunities apply equally to other marine bioproducts.

In maritime research, marine specimens from oceans must be collected by strictly following ethical and environmental guidelines. Most importantly, existing marine sample collections, including extract and pure compound libraries should form an integral part of the study materials. New biotechnological production techniques and green chemistry extraction techniques should be developed. Bioactive compounds should get supplied and optimised for biological assays via synthetic chemistry. The challenge facing the marine biotechnology industry in the next millenium is to identify new sources of marine bioproducts, to develop novel screening technologies, and to provide a sustainable source of supply.

\section{Acknowledgements \\ $\nabla$}

Great thanks are due to all partners and collaborators of the MAREX project. MAREX, Exploring Marine Resources for Bioactive Compounds: From Discovery to Sustainable Production and Industrial Applications 2010-2014 is funded by the European Union Seventh Framework Programme grant no. FP7-KBBE2009-3-245137 and is sincerely acknowledged.

\section{Conflict of Interest}

$\nabla$

The authors declare no conflict of interest.

\section{References}

1 Blunt JW, Munro MHG. Dictionary of marine natural products. Boca Raton: Chapmann \& Hall/CRC; 2007 (Available at http://dmnp.chemnetbase.com/intro/index.jsp. Accessed July 2, 2014.)

2 Mora C, Tittensor DP, Adl S, Simpson AGB, Worm B. How many species are there on Earth and in the ocean? PLoS Biol 2011; 9: e1001127

3 Sennet SH. Marine chemical ecology: applications in marine biomedical prospecting. In: McClintock JB, Baker BJ, editors. Marine chemical ecology. Boca Raton: CRC Press; 2001: 523-542

4 Blunt JW, Copp BR, Keyzers RA, Munro MHG, Prinsep MR. Marine natural products. Nat Prod Rep 2014; 31: 160-258

5 Blunt JW, Copp BR, Keyzers RA, Munro MHG, Prinsep MR. Marine natural products. Nat Prod Rep 2013; 30: 237-323

6 Cragg GM, Newman DJ. Natural products: a continuing source of novel drug leads. Biochim Biophys Acta 2013; 1830: 3670-3695

7 Mayer AM, Glaser KB, Cuevas C, Jacobs RS, Kem W, Little RD, McIntosh $J M$, Newman DJ, Potts BC, Shuster DE. The odyssey of marine pharmaceuticals: a current pipeline perspective. Trends Pharmacol Sci 2010; 31: $255-265$

8 Cuevas C, Pérez M, Martín MJ, Chicharro JL, Fernández-Rivas C, Flores M, Francesch A, Gallego P, Zarzuelo M, de La Calle F, García J, Polanco C, Rodríguez I, Manzanares I. Synthesis of ecteinascidin ET-743 and phthalascidin Pt-650 from cyanosafracin B. Org Lett 2000; 2: 2545-2548

9 Kem W, Soti F, Wildeboer K, LeFrancois S, MacDougall K, Wei DQ Chou $K C$, Arias HR. The nemertine toxin anabaseine and its derivative DMXBA (GTS-21): chemical and pharmacological properties. Mar Drugs 2006; 4: 255-273 
10 Molinski TF, Dalisay DS, Lievens SL, Saludes JP. Drug development from marine natural products. Nat Rev Drug Discov 2009; 8: 69-85

11 Coll M, Carreras M, Ciercoles C, Cornax MJ, Gorelli G, Morote E, Saez R. Assessing fishing and marine biodiversity changes using fishers' perceptions: the Spanish Mediterranean and Gulf of Cadiz case study. PLoS One 2014; 9: e85670/1-e85670/15

12 Cragg GM, Katz F, Newman DJ, Rosenthal J. Legal and ethical issues involving marine biodiscovery and development. In: Fattorusso E, Gerwick WH, Taglialatela-Scafati O, editors. Handbook of marine natural products. Dordrecht: Springer; 2012: 1314-1342

13 Gareth RJ, Jennifer MG. The experience and evolution of trust: implications for cooperation and teamwork. Acad Manage Rev 1998; 23: 531546

14 Kornprobst JM. Encyclopedia of marine natural products, Volume 1. Weinheim: Wiley-Blackwell; 2010: 43-169, 447

15 Rothschild LJ, Mancinelli RL. Life in extreme environments. Nature 2001; 409: 1092-1101

16 Thomas TRA, Kavlekar DP, LokaBharathi PA. Marine drugs from spongemicrobe association-A review. Mar Drugs 2010; 8: 1417-1468

17 Felczykowska A, Bloch SK, Nejman-Faleńczyk B, Barańska S. Metagenomic approach in the investigation of new bioactive compounds in the marine environment. Acta Biochim Pol 2012; 59: 501-505

18 Butler MS, Blaskovich MA, Cooper MA. Antibiotics in the clinical pipeline in 2013. J Antibiot 2013; 66: 571-591

19 Jang KH, Nam SJ, Locke JB, Kauffman CA, Beatty DS, Paul LA, Fenical W. Anthracimycin, a potent anthrax antibiotic from a marine-derived actinomycete. Angew Chem Int Ed 2013; 52: 7822-7824

20 Mahajan G, Thomas B, Parab R, Patel ZE, Kuldharan S, Yemparala V, Mishra PD, Ranadive P, D'Souza L, Pari K, Girish HS. In vitro and in vivo activities of antibiotic PM181104. Antimicrob Agents Chemother 2013; 57: 5315-5319

21 Singh S, Kate BN, Banerjee UC. Bioactive compounds from cyanobacteria and microalgae: an overview. Crit Rev Biotechnol 2005; 25: 73-95

22 Burja AM, Banaigs B, Abou-Mansourc E, Burgess JG, Wright PC. Marine cyanobacteria-a prolific source of natural products. Tetrahedron 2001; 57: 9347-9377

23 Welker M, von Döhren H. Cyanobacterial peptides - nature's own combinatorial biosynthesis. FEMS Microbiol Rev 2006; 30: 530-563

24 Cohen Z, Margheri MC, Tomaselli L. Chemotaxonomy of cyanobacteria. Phytochemistry 1995; 40: 1155-1158

25 Welker M, Brunke M, Preussel K, Lippert I, von Döhren H. Diversity and distribution of Microcystis (Cyanobacteria) oligopeptide chemotypes from natural communities studied by single-colony mass spectrometry. Microbiology 2004; 150: 1785-1796

26 Welker M, Christiansen G, von Döhren H. Diversity of coexisting Planktothrix (Cyanobacteria) chemotypes deduced by mass spectral analysis of microystins and other oligopeptides. Arch Microbiol 2004; 182: 288298

27 Diehnelt CW, Dugan NR, Peterman SM, Budde WL. Identification of microcystin toxins from a strain of Microcystis aeruginosa by liquid chromatography introduction into a hybrid linear ion trap - Fourier transform ion cyclotron resonance mass spectrometer. Anal Chem 2006; 78: 501-512

28 Walker M, Erhard M. Consistency between chemotyping of single filaments of Planktothrix rubescens (Cyanobacteria) by MALDI-TOF and the peptide patterns of strains determined by HPLC-MS. J Mass Spectrom 2007; 42: 1062-1068

29 Shimizu Y. Microalgal metabolites. Chem Rev 1993; 93: 1685-1698

30 Daranas AH, Norte M, Fernández JJ. Toxic marine microalgae. Toxicon 2001; 39: 1101-1132

31 Nicolaou KC, Aversa RJ. Maitotoxin: an inspiration for synthesis. Isr J Chem 2011; 51: 359-377

32 Matsubara K. Recent advances in marine algal anticoagulants. Curr Med Chem Cardiovasc Hematol Agents 2004; 2: 13-19

33 Ekanayake PM, Nikapitiya C, De Zoysa M, Whang I, Kim SJ, Lee J. Novel anticoagulant compound from fermented red alga Pachymeniopsis elliptica. Eur Food Res Technol 2008; 227: 897-903

34 Pushpamali WA, Nikapitiya C, De Zoysa M, Whang I, Kim SJ, Lee J. Isolation and purification of an anticoagulant from fermented red seaweed Lomentaria catenata. Carbohydr Polym 2008; 73: 274-279

35 de Nys R, Steinberg PD. Linking marine biology and biotechnology. Curr Opin Biotechnol 2002; 13: 244-248

36 Duarte K, Rocha-Santos TAP, Freitas AC, Duarte AC. Analytical techniques for discovery of bioactive compounds from marine fungi. Trends Anal Chem 2012; 34: 97-110
37 Bergmann W, Feeney RJ. Contributions to the study of marine products. XXXII. The nucleosides of sponges I. J Org Chem 1951; 16: 981-987

38 Lemaire P. Evolutionary crossroads in developmental biology: the tunicates. Development 2011; 138: 2143-2152

39 Lewis RJ, Garcia ML. Therapeutic potential of venom peptides. Nat Rev Drug Discov 2003; 2: 790-802

40 Clark RJ, Jensen J, Nevin ST, Callaghan BP, Adams DJ, Craik DJ. The engineering of an orally active conotoxin for the treatment of neuropathic pain. Angew Chem Int Ed 2010; 49: 6545-6548

41 Rocha J, Peixe L, Gomes NCM, Calado R. Cnidarians as a source of new marine bioactive compounds-an overview of the last decade and future steps for bioprospecting. Mar Drugs 2011; 9: 1860-1886

42 Mackie GO. What's new in cnidarian biology? Can J Zool 2002; 80: 1649-1653

43 Nelson JS. Fishes of the world, 4th edition. Hoboken: John Wiley \& Sons Inc; 2006: 2-5

44 Reddy LH, Couvreur P. Squalene: a natural triterpene for use in disease management and therapy. Adv Drug Deliv Rev 2009; 61: 1412-1426

45 Nieto FR, Cobos EJ, Tejada MÁ, Sánchez-Fernández C, González-Cano R, Cendán $C R$. Tetrodotoxin (TTX) as a therapeutic agent for pain. Mar Drugs 2012; 10: 281-305

46 Esteves-Ferreira AA, Correa DM, Carneiro APS, Rosa RM, Loterio R, Araujo WL. Comparative evaluation of different preservation methods for cyanobacterial strains. J Appl Phycol 2013; 25: 919-929

47 Guillard RRL. Purification methods for microalgae. In: Andersen AR, editor. Algal culturing techniques. China: Elsevier Academic Press; 2005: 117-132

48 Bohlin L, Alsmark C, Goeransson U, Klum M, Weden C, Backlund A. In: Tringali C, editor. Bioactive compounds from natural sources, 2 nd edition. Boca Raton: CRC Press; 2012: 1-36

49 Eriksen NT. The technology of microalgal culturing. Biotechnol Lett 2008; 30: 1525-1536

50 Schmidt RS. Heterotrophic high cell-density fed-batch cultures of the phycocyanin-producing red alga Galdieria sulphuraria. Biotechnol Bioengin 2005; 90: 77-84

51 Kupchan SM, Britton RW, Ziegler MF, Sigel CW. Bruceantin, a new potent antileukemic simaroubolide from Brucea antidysenterica. J Org Chem 1973; 38: 178-179

52 Donia MS, Ruffner DE, Cao S, Schmidt EW. Accessing the hidden majority of marine natural products through metagenomics. Chembiochem 2011; $12: 1230-1236$

53 Breton RC, Reynolds WF. Using NMR to identify and characterize natural products. Nat Prod Rep 2013; 30: 501-524

54 Ghitti M, Musco G, Spitaleri A. NMR and computational methods in the structural and dynamic characterization of ligand-receptor interactions. Adv Exp Med Biol 2014; 805: 271-304

55 Matsumori N, Kaneno D, Murata M, Nakamura H, Tachibana K. Stereochemical determination of acyclic structures based on carbon-proton spin-coupling constants. A method of configuration analysis for natural products. J Org Chem 1999; 64: 866-876

56 Seco JM, Quiñoá E, Riguera R. The assignment of absolute configuration by NMR. Chem Rev 2004; 104: 17-117

57 Lee JA, Berg EL. Neoclassic drug discovery: the case for lead generation using phenotypic and functional approaches. J Biomol Screen 2013; 18: $1143-1155$

58 Fishburn CS. Translational research: the changing landscape of drug discovery. Drug Discov Today 2013; 18: 487-494

59 Lang PK, Yeow K, Nichols A, Sheer A. Cellular imaging in drug discovery. Nat Rev Drug Discov 2006; 5: 343-356

60 Lee JA, Uhlik MT, Moxham CM, Tomandl D, Sall DJ. Modern phenotypic drug discovery is a viable, neoclassic pharma strategy. J Med Chem 2012; 55: 4527-4538

61 Sams-Dodd F. Is poor research the cause of the declining productivity of the pharmaceutical industry? An industry in need of a paradigm shift. Drug Discov Today 2013; 18: 211-217

62 Harvey $A L$. Natural products as a screening resource. Curr Opin Chem Biol 2007; 11: 480-484

63 Bugni TS, Richards B, Bhoite L, Cimbora D, Harper MK, Ireland CM. Marine natural product libraries for high-throughput screening and rapid drug discovery. J Nat Prod 2008; 71: 1095-1098

64 Tawfike AF, Viegelmann C, Edrada-Ebel R. Metabolomics and dereplication strategies in natural products. Methods Mol Biol 2013; 1055: 227244 
65 Larsen TO, Smedsgaard J, Nielsen KF, Hansen ME, Frisvad JC. Phenotypic taxonomy and metabolite profiling in microbial drug discovery. Nat Prod Rep 2005; 22: 672-695

66 Koehn FE, Carter GT. The evolving role of natural products in drug discovery. Nat Rev Drug Discov 2005; 4: 206-220

67 Florence GJ, Gardner NM, Ian Paterson I. Development of practical syntheses of the marine anticancer agents discodermolide and dictyostatin. Nat Prod Rep 2008; 25: 342-375

68 Chen JC, Chen XC, Willot M, Zhu J. Asymmetric total syntheses of ecteinascidin 597 and ecteinascidin 583. Angew Chem Int Ed 2006; 45 : 8028-8032

69 Shang S, Tan DS. Advancing chemistry and biology through diversityoriented synthesis of natural product-like libraries. Curr Opin Chem Biol 2005; 9: 248-258

70 Mantovani A, Balkwill F. RalB signaling: a bridge between inflammation and cancer. Cell 2006; 127: 42-44

71 Castellani P, Balza E, Rubartelli A. Inflammation, DAMPs, tumor development, and progression: a vicious circle orchestrated by redox signaling. Antioxid Redox Sign 2014; 20: 1086-1097

72 Luo JL, Kamata $H$, Karin M. IKK/NF- $\kappa$ B signaling: balancing life and death - a new approach to cancer therapy. J Clin Invest 2005; 115: 2625-2632

73 Luo JL, Maeda S, Hsu LC, Yagita H, Karin M. Inhibition of NF- $k B$ in cancer cells converts inflammation- induced tumor growth mediated by TNF $\alpha$ to TRAIL-mediated tumor regression. Cancer Cell 2004; 3: 297-305

74 Karin M, Greten FR. NF- $k$ B: linking inflammation and immunity to cancer development and progression. Nat Rev Immunol 2005; 10: 749-759

75 Grienke U, SilkeJ, Tasdemir D. Bioactive compounds from marine mussels and their effects on human health. Food Chemistry 2014; 142: 48-60

$76 \mathrm{Kim}$ JA, Kim SK. Bioactive peptides from marine sources as potential antiinflammatory therapeutics. Curr Protein Pept Sci 2013; 14: 177-182

77 Moczydlowski EG. The molecular mystique of tetrodotoxin. Toxicon 2013; 63: 165-183

78 Greenberg EN. Ziconitide. J Pain Palliat Care Pharmacother 2011; 25: 380-381

79 Adams DJ, Berecki G. Mechanisms of conotoxin inhibition of N-type (Cav2.2) calcium channels. Biochim Biophys Acta 2013; 1828: 16191628

80 Kresse H, Belsey MJ, Rovin H. The antibacterial drugs market. Nat Rev Drug Discov 2007; 6: 19-20

81 Weaver SC, Barrett A. Transmission cycles, host range, evolution and emergence of arboviral disease. Nat Rev Microbiol 2004; 2: 789-801

82 Pialoux G, Gaüzère BA, Jauréguiberry S, Strobel M. Chikungunya, an epidemic arbovirosis. Lancet Infect Dis 2007; 7: 319-327

83 Rezza G, Nicoletti L, Angelini R, Romi R, Finarelli AC, Panning M, Cordioli P, Fortuna C, Boros S, Magurano F, Silvi G, Angelini P, Dottori M, Ciufolini MG, Majori GC, Cassone A. Infection with chikungunya virus in Italy: an outbreak in a temperate region. Lancet 2007; 370: 1840-1846

84 Brummer-Korvenkontio M, Vapalahti O, Kuusisto P, Saikku P, Manni T, Koskela P, Nygren T, Brummer-Korvenkontio H, Vaheri A. Epidemiology of Sindbis virus infections in Finland 1981-96: possible factors explaining a peculiar disease pattern. Epidemiol Infect 2002; 129: 335-345

85 Mayer AMS, Jacobson PB, Fenical W, Jacobs RS, Glaser KB. Pharmacological characterization of the pseudopterosins: novel anti-inflammatory natural products isolated from the Caribbean soft coral, Pseudopterogorgia elisabethae. Life Sci 1998; 62: PL401-PL407

86 Castanaro J, Lasker HR. Effects of clipping on growth of colonies of the Caribbean gorgonian Pseudopterogorgia elisabethae. Invertebr Biol 2003; 122: 299-307

87 Moore A. Blooming prospects? Humans have eaten seaweed for millennia; now microalgae are to be served up in a variety of novel health supplements, medicaments and preparations. EMBO Rep 2001; 2: 462-464

88 Zhu D, Niu J, Shen S, Wang G. An economic assessment of astaxanthin production by large scale cultivation of Haematococcus pluvialis. Biotechn Adv 2011; 29: 568-574

89 Picot C, Nguyen TA, Roudot AC, Parent-Massin DA. Preliminary risk assessment of human exposure to phycotoxins in shellfish: a review. Hum Ecol Risk Assess 2011; 17: 328-366

90 Vilarino N, Louzao MC, Fraga M, Rodriguez LP, Botana LM. Innovative detection methods for aquatic algal toxins and their presence in the food chain. Anal Bioanal Chem 2013; 405: 7719-7732

91 Campbell $K$. Biosensor technology for marine toxin analysis. In: Botana LM, editor. Seafood and freshwater toxins, pharmacology, physiology, and detection, 3rd edition. Boca Raton: CRC Press; 2014: 347-366
92 Eggins BR. Chemical sensors and biosensors. New York: John Wiley \& Sons Inc; 2002: 5-9

93 Huang PJJ, Khimji I, Liu J. Immobilization of fluorescent aptamer biosensors on magnetic microparticles and its potential application for ocean sensing. In: Tiquia-Arashiro SM, editor. Molecular biological technologies for ocean sensing. Dearborn: Humana Press; 2012: $151-168$

94 Weigl BH, Bardell RL, Cabrera CR. Lab-on-a-chip for drug development. Adv Drug Deliv Rev 2003; 55: 349-377

95 Erickson $D$, Li D. Integrated microfluidic devices. Anal Chim Acta 2004; 507: 11-26

96 Marquette CA, Coulet PR, Blum LJ. Semi-automated membrane based chemiluminescent immunosensor for flow injection analysis of okadaic acid in mussels. Anal Chim Acta 1999; 398: 173-182

97 Desmet C, Blum LJ, Marquette CA. Multiplex microarray ELISA versus classical ELISA, a comparison study of pollutant sensing for environmental analysis. Environ Sci Process Impacts 2013; 15: 1876-1882

98 Yakes BJ, Prezioso SM, DeGrasse SL. Developing improved immunoassays for paralytic shellfish toxins: the need for multiple, superior antibodies. Talanta 2012; 99: 668-676

99 Kulagina NV, Twiner MJ, Hess P, McMahon T, Satake M, Yasumoto T, Ramsdell JS, Doucette GJ, Ma W, O'Shaughnessy TJ. Detection of marine toxins, brevetoxin-3 and saxitoxin, in seawater using neuronal networks. Environ Sci Technol 2006; 40: 578-583

100 Strik WA, Ördög V, Van Staden J, Jäger K. Cytokinin- and auxin-like activity in Cyanophyta and microalgae. J Appl Phycol 2002; 14: 215-221

101 Karthikeyan N, Prasanna R, Nain L, Kaushik BD. Evaluating the potential of plant growth promoting cyanobacteria as inoculants for wheat. Eur J Soil Biol 2007; 43: 23-30

102 Peuthert A, Chakrabarti S, Pflugmache S. Uptake of microcystins-LR and -LF (cyanobacterial toxins) in seedlings of several important agricultural plant species and the correlation with cellular damage (lipid peroxidation). Environ Toxicol 2007; 22: 436-442

103 Zaccaro MC, Kato A, Zulpa G, Storni MM, Steyerthal N, Lobasso K, Stella AM. Bioactivity of Scytonema hofmanni (Cyanobacteria) in Lilium alexandrae in vitro propagation. Electr J Biotechnol 2006; 9: 210-214

104 Berry JP, Gantar M, Perez MH, Berry G, Noriega FG. Cyanobacterial toxins as allelochemicals with potential applications as algaecides, herbicides and insecticides. Mar Drugs 2008; 6: 117-146

105 Hellio C, Tsoukatou M, Maréchal JP, Aldred N, Beaupoil C, Clare AS, Vagias $C$, Roussis $V$. Inhibitory effects of Mediterranean sponge extracts and metabolites on larval settlement of the barnacle Balanus amphitrite. Mar Biotechnol 2005; 7: 297-305

106 Chelossi E, Mancini I, Sepčić K, Turk T, Faimali M. Comparative antibacterial activity of polymeric 3-alkylpyridinium salts isolated from the Mediterranean sponge Reniera sarai and their synthetic analogues. Biomol Engin 2006; 23: 317-323

107 Sjoegren M, Johnson AL, Hedner E, Dahlstroem M, Goeransson U, Shirani $H$, Bergman J, Jonsson PR, Bohlin L. Antifouling activity of synthesized peptide analogs of the sponge metabolite barettin. Peptides 2006; 27 : 2058-2064

108 Sjoegren M, Dahlstroem M, Goeransson U, Jonsson P, Bohlin L. Recruitment in the field of Balanus improvisus and Mytilus edulis in response to the antifouling cyclopeptides barettin and 8,9-dihydrobarettin from the marine sponge Geodia barrette. Biofouling 2004; 20: 291-297

109 Hall-Stoodley L, Costerton JW, Stoodley P. Bacterial biofilms: from the natural environment to infectious diseases. Nature Rev Microbiol 2004; 2: 95-108

110 Lear G, Lewis GD. Microbial biofilms: current research and applications. Norfolk: Caister Academic Press; 2012: 1-228

111 Matz C, Webb JS, Schupp PJ, Phang SY, Penesyan A, Egan S, Steinberg P, Kjelleberg $S$. Marine biofilm bacteria evade eukaryotic predation by targeted chemical defense. PLoS One 2008; 3: 1-7

112 Matz C. Struggle, communication, cooperation. Biochemical interactions in marine biofilms. Chem Unserer Zeit 2009; 43: 160-167

113 Skogman M, Vuorela P, Fallarero A. Combining biofilm matrix measurements with biomass and viability assays in susceptibility assessments of antimicrobials against Staphylococcus aureus biofilms. J Antibiot 2012; 65: 453-459

114 Manner S, Skogman M, Goeres D, Vuorela P, Fallarero A. Systematic exploration of natural and synthetic flavonoids for inhibition of Staphylococcus aureus biofilms. Int J Mol Sci 2013; 14: 19434-19451

115 Ausbacher D, Fallarero A, Määttänen A, Kujala J, Ström MB, Vuorela PM. Staphylococcus aureus biofilm susceptibility to small and potent $\beta 2,2-$ amino acid derivatives. Biofouling 2014; 30: 81-93 